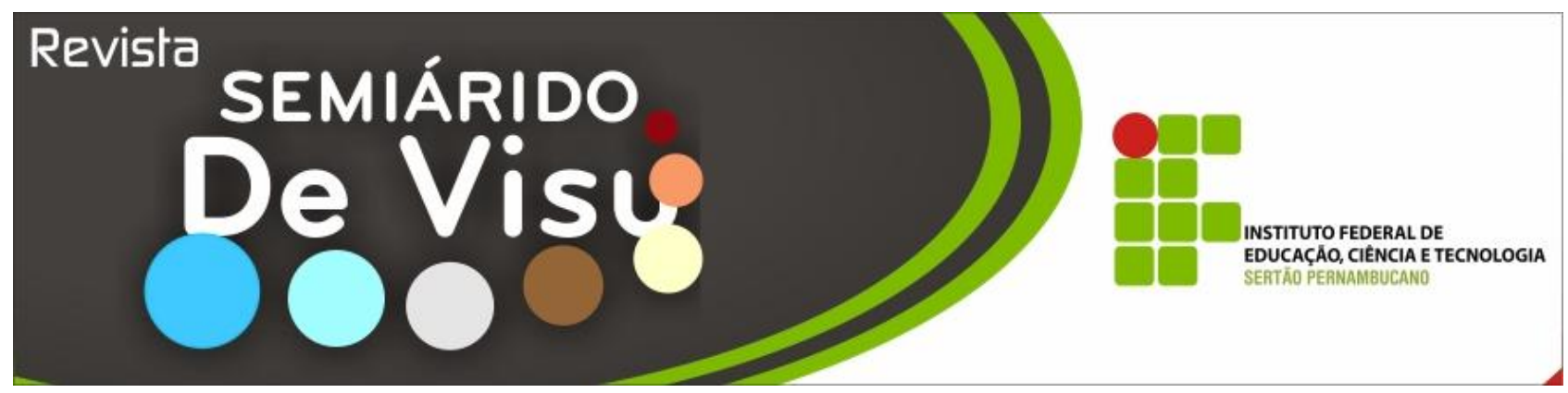

\title{
Estudo comparativo da desidratação de frutas para fins de infusão, por método tradicional e liofilização
}

\author{
Laurena Rayanne Vieira Moraes ${ }^{1}$, Luciana Cavalcanti de Azevêdo ${ }^{1}$, Vivianni Marques Leite \\ Santos $^{2}$, Ted Jhonson Vasconcelos Leitão ${ }^{2}$ \\ 1.Instituto Federal de Educação, Ciência e Tecnologia do Sertão Pernambucano - IF SERTÃO-PE, Campus \\ Petrolina, Rodovia BR 407, Km 08, s/n, Bairro Jardim São Paulo, CEP: 56.3000-000, E-mail: \\ lucianac.azevedo@ifsertao-pe.edu.br. \\ 2. Universidade Federal do Vale do São Francisco. Colegiado de Engenharia de Produção, Juazeiro/BA
}

\begin{abstract}
RESUMO: As frutas produzidas em todo o Brasil têm sido frequentemente utilizadas em estudos que envolvem desenvolvimento de novos produtos. Uma excelente alternativa tecnológica para a utilização de algumas frutas é o processo de secagem, para que sejam destinados à infusão (chá), uma vez que poderão ser utilizados como matériaprima, além dos frutos in natura, os subprodutos industriais, que encerram elevados teores de nutrientes. Muitas vantagens estão associadas ao processo de secagem, dentre as quais: a facilidade na conservação do produto; estabilidade dos componentes aromáticos à temperatura ambiente por longos períodos de tempo; proteção contra degradação enzimática e oxidativa; redução do seu peso; economia de energia por não necessitar de refrigeração e a disponibilidade do produto durante qualquer época do ano. No presente estudo foram utilizadas frutas regionais submetidas ao processo de secagem, com finalidade de uso em infusões (chás), avaliando o impacto sensorial conferido por estes frutos à bebida e a aceitação pelos consumidores, sendo utilizados os frutos: maracujá, maracujá-do-mato, resíduo da acerola, abacaxi, melão, tamarindo e manga cv. Tommy atkins. Foram realizadas também análises físicoquímicas nas frutas citadas referentes aos teores de umidade e sólidos solúveis totais (SST) e atividade de água (aw). Os frutos desidratados por secagem convencional apresentaram valores de umidade média em torno de 9,91 a 12,65\%, enquanto para os frutos liofilizados, estes valores consistiram de uma faixa mais ampla, variando entre 8,60 a 27,68\%. Além da diferenciação entre os valores finais de umidade, foi possível perceber que a secagem convencional apresenta também algumas vantagens em relação ao método por liofilização, no que diz respeito ao aroma e ao sabor das frutas secas obtidas, e integridade física se comparado ao fruto in natura. De maneira geral, todas as amostras de chá foram consideradas aprovadas, do ponto de vista sensorial, uma vez que obtiveram notas acima de sete para a maioria dos atributos sensoriais.
\end{abstract}

Palavras-chave: secagem, umidade, análise sensorial

\section{Comparative study of the dehydration of fruits and physico-chemical for infusion (tea) by traditional method and lyophilization}

\begin{abstract}
The fruit produced in Brazil have often been used in studies involving new product development. An excellent alternative technology for the use of certain fruits is the drying process, which are intended for infusion (tea), since they can be used as raw material in addition to the fresh fruit, the industrial byproducts, that contain high concentration of nutrients. Many advantages are associated with the drying process, including: the ease of storage of the product, stability of the aromatic constituents at room temperature for long periods of time, protection against enzymatic degradation and oxidation, reduction in weight; energy savings by not require refrigeration and product availability during any time of year (Park, 2001). In the present study we used local fruit subjected to the drying
\end{abstract}


Laurena Rayanne Vieira Moraes et al.

process, with the purpose of use in infusions (teas), evaluating the nutritional value offered by these fruits to the drink and consumer acceptance, and use the fruit: passion fruit, passion fruit-eating fox is the residue of acerola, pineapple, melon, tamarind and mango cv. Tommy atkins. They were analyzed in fruit physicochemical cited regarding the moisture content and total soluble solids (TSS) and water activity (aw). The dehydrated fruits by conventional drying moisture values average around 9.91 to $12.65 \%$, while for fruit lyophilized, these figures consisted of a wider range, varying from 8.60 to $27.68 \%$. Besides the difference between the final values of humidity, it is noted that conventional drying has also some advantages over the method by lyophilization, as regards the smell and taste of dried fruit obtained, and the physical integrity compared to the fruit in natura. In general, all samples were considered tea approved, the sensory standpoint since notes obtained above seven for most sensory attributes.

Keywords: Drying, moisture, sensory analysis

\section{Introdução}

$\mathrm{O}$ Pólo Petrolina-Juazeiro se encontra na região do Submédio São Francisco e tem como foco de sua eco $\neg$ nomia a produção irrigada de frutas. A região possui as condições naturais necessárias ao desenvolvimento dessa atividade, combinando índices de insolação e calor, aliado ao clima seco do semiárido e um solo favorável à irriga $\neg$ ção. Esses fatores permitem várias safras anuais e uma maior qualidade do produto, tornando o Pólo competitivo no mercado mundial de frutas (FILHO, 2008).

Este potencial da região tem atraído muitas empresas agrícolas de produção e beneficiamento, abrindo espaço para novos mercados e valorizando ainda mais os frutos produzidos no Vale do São Francisco. Indústrias de polpas e concentrados, doces, sucos, água de coco, sorvetes e vinhos são exemplos de empreendimentos agroindustriais instalados na região para gerar alternativas de direcionamento de uma parte da produção de frutas. Mesmo já contando com esta diversidade de produtos, novas possibilidades de agregação de valor estão sendo estudadas por produtores locais para garantir uma maior diversificação de mercado.

Uma excelente alternativa tecnológica e econômica seria a utilização de algumas dessas frutas em processos de secagem, para que sejam destinados à infusão (chá), uma vez que poderão ser utilizados como matéria-prima, além dos frutos in natura, os subprodutos industriais, que encerram elevados teores de nutrientes. Muitas vantagens estão associadas ao processo de secagem, dentre as quais se tem: a facilidade na conservação do produto; estabilidade dos componentes aromáticos à temperatura ambiente por longos períodos de tempo; proteção contra degradação enzimática e oxidativa; redução do seu peso; economia de energia por não necessitar de refrigeração e a disponibilidade do produto durante qualquer época do ano (PARK, 2001). Além disso, os frutos submetidos à secagem apresentam elevados teores de minerais e outros nutrientes que apresentam benefícios à saúde.

O presente estudo propõe a utilização de frutos como: maracujá, maracujá-do-mato, acerola, abacaxi, melão, tamarindo e manga cv. Tommy atkins em processos de secagem, com finalidade de uso em infusões, avaliando o impacto sensorial conferido por estes frutos à bebida, de acordo com a técnica de secagem utilizada (secagem convencional ou liofilização), e a aceitação pelos consumidores.

\section{Material e métodos}

\section{Materiais}

Foram utilizados neste estudo os frutos maduros de: maracujá, maracujá-do-mato, resíduo da acerola, abacaxi, melão, tamarindo e manga cv. Tommy atkins. Os frutos foram adquiridos no mercado local e levados ao Laboratório Experimental de Alimentos (LEA) do IF SERTÃO-PE, bem como ao laboratório de Engenharia de Produção da UNIVASF.

\section{Análises Físico-Químicas}


Laurena Rayanne Vieira Moraes et al.

Tanto os frutos in natura quanto os seus derivados desidratados e liofilizados, foram submetidos às análises físico-químicas de sólidos solúveis totais (SST), umidade e atividade de água (aW) seguindo a metodologia descrita pelo IAL (2005).

O teor de sólidos solúveis ( ${ }^{\circ}$ Brix) foi obtido por refratometria, utilizando refratômetro ABBE de bancada (Marca Biobrix). Para determinação da umidade foi utilizada estufa a $105^{\circ} \mathrm{C}$ (Mod. ORION, Marca FANEM). A atividade de água foi medida utilizando o aparelho portátil denominado Decagon de marca BrasEq, modelo Pawkit, faixa de medição de aW de 0,00 a 1,00.

\section{Testes de desidratação}

Após a lavagem e sanitização dos frutos em água clorada a 40ppm, os mesmos foram fracionados para serem submetidos à secagem em secador de fluxo contínuo (Figura 1), com controle de temperatura $\left(70^{\circ} \mathrm{C}\right)$. Para a realização das secagens foi utilizado cerca de $5 \mathrm{Kg}$ de cada tipo de fruta. Durante a secagem foi estabelecido o intervalo de 1 hora para a avaliação do comportamento de secagem de cada fruta.



Figura1. Secador de fluxo contínuo

\section{Testes de Liofilização}

Após a lavagem e sanitização dos frutos em água clorada a 40ppm, os mesmos foram fracionados para serem submetidos inicialmente a um congelamento numa temperatura de $-45^{\circ} \mathrm{C}$ por um período de 24 horas. Em seguida foram liofilizadas por um período de 24 horas onde ainda foi constatada umidade indesejável sendo necessário repetir o mesmo procedimento a depender de cada fruta a ser liofilizada. O equipamento de liofilização utilizado foi o LIOBRAS modelo L101 para 8 frascos (Figura 2). 
Laurena Rayanne Vieira Moraes et al.

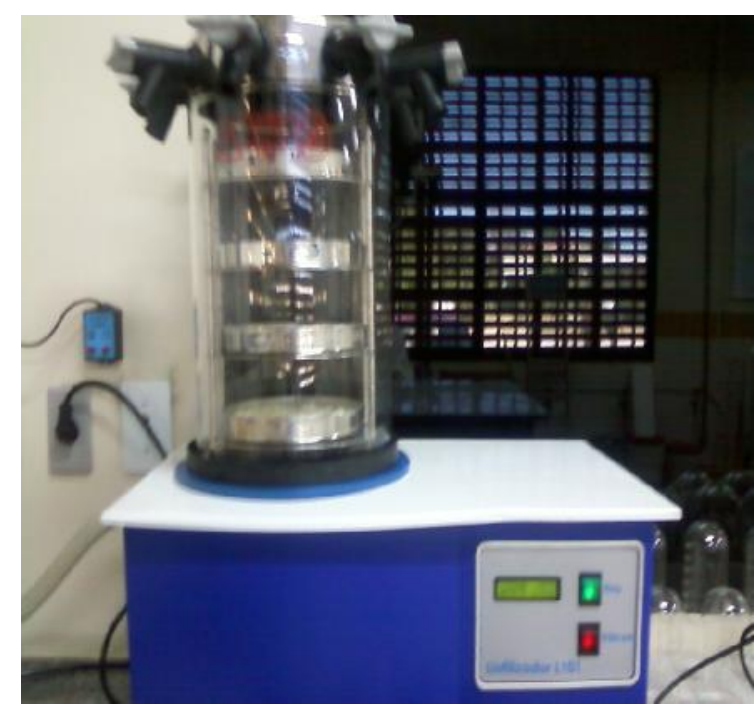

Figura 2. Liofilizador - LIOBRAS modelo L101

\section{Análise Sensorial}

Após a liofilização e secagem dos frutos, foi feito o preparo dos sachês, seguido de análise sensorial. Cada sachê possuía $3 \mathrm{~g}$ de amostra. Os chás eram servidos em xicara apropriada para esse fim, e submetido à infusão, com $100 \mathrm{~mL}$ de água quente (aproximadamente $90^{\circ} \mathrm{C}$ ), para que houvesse melhor extração e facilitasse a análise. Foram analisados quatro aspectos: cor, sabor, aroma e características originais da fruta.

As infusões obtidas das amostras desidratadas pelos dois métodos propostos foram submetidas a testes sensoriais comparativos, para que os provadores pudessem avaliar se as características sensoriais dos frutos foram mantidas nos derivados desidratados. Foram realizados também e testes sensoriais quantitativos, para pontuação das características sensoriais.

O teste sensorial dos chás foi realizado por um painel formado por 20 (vinte) degustadores não treinados de ambos os sexos, composto por servidores do IF SERTÃO - PE, utilizando um formulário com escala hedônica estruturada contendo nota mínima 1 (desgostei extremamente) e nota máxima 9 (gostei extremamente), conforme metodologia adaptada de Minim (2006). As amostras ofertadas para análise foram devidamente codificadas e oferecidas em xícaras de vidro transparente, apropriadas para chá e com capacidade para $240 \mathrm{~mL}$.

\section{Resultados e discussão}

\section{Análises físico-químicas}

Os resultados das análises físicoquímicas nos frutos in natura estão mostrados na Tabela 1, enquanto os resultados dos frutos desidratados são mostrados na Tabela 2 e dos frutos liofilizados na Tabela 3 .

Pode ser observado que, de acordo com a Tabela 1, todos os frutos in natura analisados apresentaram elevado teor de umidade. Valores semelhantes a este foram encontrados na tabela Taco (2011): abacaxi (86,3\%), manga (85,8\%), maracujá $(82,9 \%)$, melão $(91,3 \%)$, tamarindo (22\%), acerola (93,6\%). De acordo com Potter e Hotchkiss (1999), as hortaliças e frutas possuem valores de umidade maiores que $70 \%$ e, frequentemente, superam $85 \%$. A determinação de umidade é uma das medidas mais importantes e utilizadas na análise de alimentos. O teor de umidade de um alimento está relacionado com sua estabilidade, qualidade e composição, e pode afetar o armazenamento, embalagens e processamento (CHAVES et al., 2004). 
Laurena Rayanne Vieira Moraes et al.

Tabela 1. Caracterização físico-química das diversas frutas in natura

\begin{tabular}{crrlccc}
\hline Frutas & ${ }^{\circ}$ Brix & $\mathbf{C V}(\%)$ & Umidade (\%) & $\mathbf{C V}(\%)$ & a.w & $\mathbf{C V}(\%)$ \\
\hline Abacaxi & 17,0 & 1,25 & 81,34 & 1,02 & $1,00 / 20,6^{\circ} \mathrm{C}$ & 0,09 \\
Melão & 6,5 & 0,00 & 92,94 & 0,09 & $1,00 / 21,3^{\circ} \mathrm{C}$ & 1,00 \\
Maracujá & 11,0 & 1,90 & 78,5 & 2,92 & $1,00 / 21,6^{\circ} \mathrm{C}$ & 0,00 \\
Maracujá-do-mato & 5,5 & 1,20 & 86,1 & 0,65 & $1,00 / 21,6^{\circ} \mathrm{C}$ & 0,00 \\
Manga & 14,5 & 2,30 & 84,11 & 0,39 & $1,00 / 20,9^{\circ} \mathrm{C}$ & 0,00 \\
Tamarindo & 8,5 & 0,00 & 25,14 & 1,39 & $0,81 / 21,4^{\circ} \mathrm{C}$ & 0,00 \\
Resíduo da acerola & 6,5 & 2,10 & 85,04 & 5,40 & $1,00 / 21,4^{\circ} \mathrm{C}$ & 0,00 \\
\hline
\end{tabular}

Tabela 2. Caracterização físico-química das diversas frutas desidratadas por secagem convencional

\begin{tabular}{ccccrcc}
\hline Frutas & ${ }^{\circ}$ Brix & $\mathbf{C V}(\%)$ & Umidade $(\%)$ & $\mathbf{C V}(\%)$ & a.w & $\mathbf{C . V}(\%)$ \\
\hline Abacaxi & 23,08 & 1,62 & 11,45 & 1,04 & $0,62 / 20,9^{\circ} \mathrm{C}$ & 0,00 \\
Melão & 52,48 & 0,65 & 11,51 & 3,47 & $0,51 / 20,6^{\circ} \mathrm{C}$ & 3,92 \\
Maracujá & 19,66 & 1,50 & 11,98 & 2,00 & $0,56 / 20,9^{\circ} \mathrm{C}$ & 0,03 \\
Maracujá-do-mato & 18,72 & 0,09 & 12,65 & 5,37 & $0,56 / 20,1^{\circ} \mathrm{C}$ & 0,00 \\
Manga & 41,33 & 0,05 & 12,21 & 3,03 & $0,64 / 20,5^{\circ} \mathrm{C}$ & 0,00 \\
Tamarindo & 17,07 & 1,90 & 11,41 & 0,00 & $0,48 / 28,2^{\circ} \mathrm{C}$ & 0,00 \\
Resíduo da acerola & 21,45 & 2,30 & 9,91 & 0,80 & $0,55 / 20,7^{\circ} \mathrm{C}$ & 0,00 \\
\hline
\end{tabular}

Tabela 3. Caracterização físico-química das diversas frutas liofilizadas

\begin{tabular}{ccccccc}
\hline Frutas & ${ }^{\circ}$ Brix & $\mathbf{C V}(\%)$ & Umidade (\%) & $\mathbf{C V}(\%)$ & a.w & $\mathbf{C V}(\%)$ \\
\hline Abacaxi & 28,71 & 2,80 & 17,06 & 1,10 & $0,70 / 28,3^{\circ} \mathrm{C}$ & 0,00 \\
Melão & 41,85 & 2,80 & 14,99 & 0,80 & $0,37 / 27,5^{\circ} \mathrm{C}$ & 2,80 \\
Maracujá & 21,20 & 0,00 & 24,99 & 0,00 & $0,73 / 28,1^{\circ} \mathrm{C}$ & 0,00 \\
Maracujá-do-mato & 13,21 & 0,00 & 27,68 & 1,77 & $0,77 / 28,1^{\circ} \mathrm{C}$ & 0,00 \\
Manga & 39,12 & 0,00 & 8,60 & 2,79 & $0,36 / 28,0^{\circ} \mathrm{C}$ & 0,00 \\
Tamarindo & 11,71 & 1,02 & 17,17 & 6,90 & $0,51 / 28,2^{\circ} \mathrm{C}$ & 0,00 \\
Resíduo da Acerola & 12,56 & 0,00 & 10,15 & 0,09 & $0,57 / 28,1^{\circ} \mathrm{C}$ & 0,00 \\
\hline
\end{tabular}

A atividade de água também é um fator que influencia diretamente a estabilidade do produto, pois representa os valores de água disponíveis na matriz sólida do alimento, indicando a relação deste conteúdo com as reações químicas e microbiológicas que determinam a deterioração do material (FIGUEIRA et al., 2004). Assim como o teor de umidade, a medida de aW de um alimento desidratado se constitui como importante informação, que norteia a previsão de vida útil do produto.

Conforme pode ser observado na Tabela 2 , os valores de umidade entre as diversas frutas desidratadas pelo método convencional estão semelhantes, variando de 9,91 a $12,65 \%$ e demonstrando maior uniformidade entre as amostras, também se considerarmos os valores de aW obtidos.
O mesmo comportamento não pôde ser observado entre os frutos desidratados pelo método de liofilização. A legislação encontrada para produtos liofilizados (Resolução CNNPA $\left.\mathrm{n}^{\circ} 12\right)$ estabelece que os produtos liofilizados obtenham máximo de $5 \%$ de umidade (BRASIL, 2008). Conforme a Tabela 3, foram encontrados valores de umidade entre 8,60 e $27,68 \%$, sendo assim apropriado em trabalhos futuros viabilizar métodos alternativos capazes de minimizar tais valores.

Os principais fatores responsáveis pelo crescimento de microrganismos em frutas estão relacionados com atividades de água superiores a 0,82 , por isso, e possível afirmar que as frutas desidratadas neste estudo poderão ser conservadas por períodos mais prolongados sem que haja deterioração por microrganismos (NORTHOLT et al., 1978). 
Laurena Rayanne Vieira Moraes et al.

Curvas de secagem por método convencional

As curvas de secagem são construídas quando se deseja avaliar o comportamento do tecido do vegetal durante a remoção da água livre presente. Trata-se de um recurso matemático bastante empregado na observação de processos de desidratação.

As curvas de secagem obtidas neste experimento são mostradas na Figura 3 . Através da observação das curvas de secagem é possível perceber a diferença de comportamento, em relação à perda de umidade, para cada fruta analisada. Vale salientar que cada fruta possui características individuais de forma, composição e estrutura. No caso do tamarindo, por exemplo, que é considerado um fruto com pouca quantidade de água e bastante rígido, percebe-se maior dificuldade em perder sua água disponível, diferente do resíduo da acerola e dos frutos de abacaxi e manga, nos quais a perda de água foi intensa já nas primeiras horas da secagem, concluindo o processo de evaporação após 7 horas. O maracujá amarelo e maracujá-do-mato também apresentaram bastante dificuldade no processo de secagem (24 horas, no mínimo), já que para ser realizado esse processo foi utilizado o fruto com casca, visando um melhor beneficiamento do produto final, resultando em menores perdas. A manga Tommy Atkins e o melão obtiveram comportamentos semelhantes, uma vez que ambos os frutos possuem valores de umidade semelhantes, e essa semelhança acaba sendo refletida no seu comportamento de secagem.
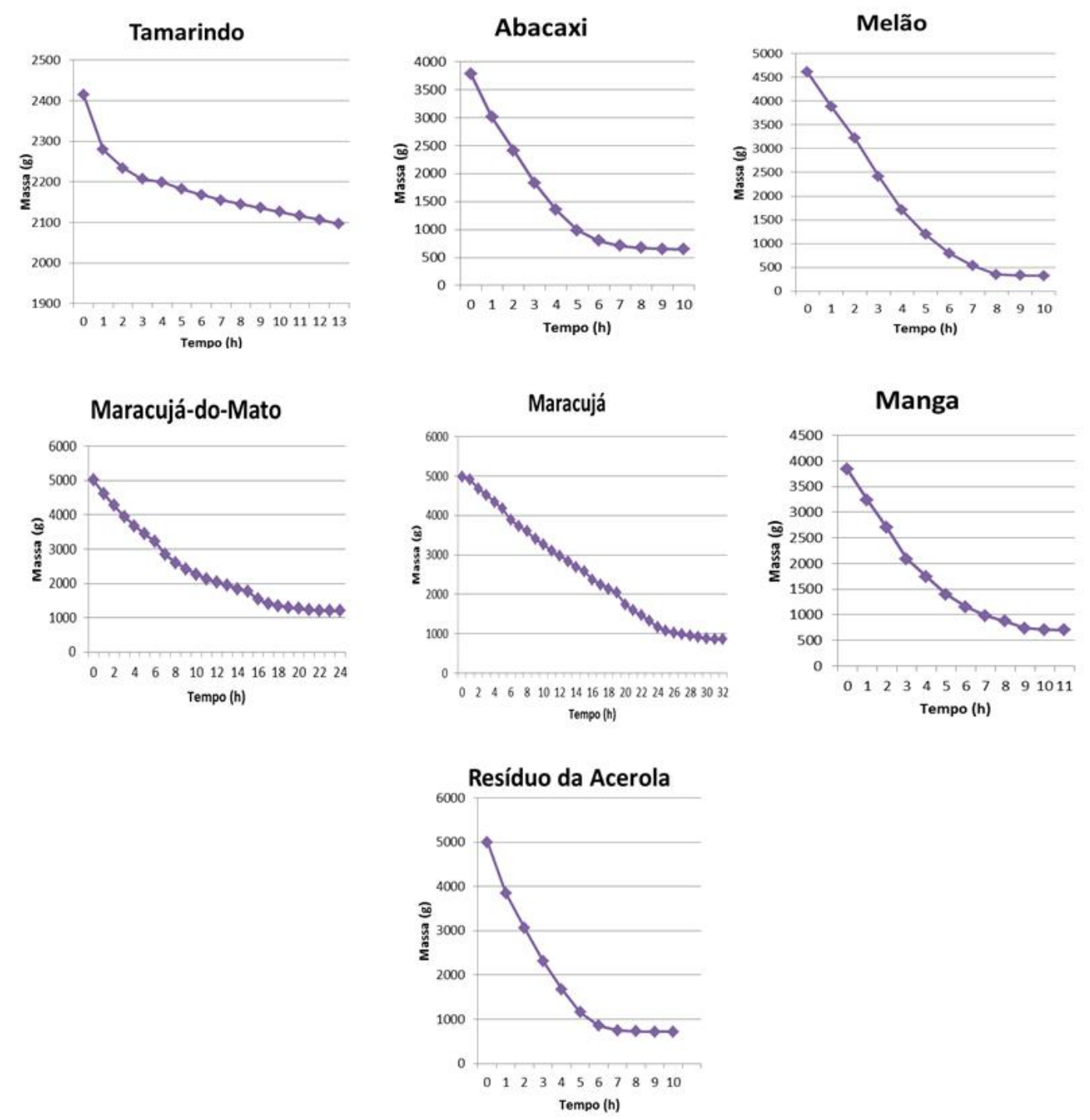

Figura 3. Curvas de secagem dos frutos estudados 
Laurena Rayanne Vieira Moraes et al.

Quanto ao rendimento de fruto desidratado, o tamarindo obteve um maior resultado perceptível, isso deve ao fato do fruto já ser considerado com uma umidade inferior $(25,14 \%)$ em relação às demais, ocasionando uma perda menor de água. Era de se esperar que, em frutas com maior percentual de umidade como o melão $(92,94 \%)$, o rendimento em fração seca fosse menor. Ou seja, no caso do melão, a grande quantidade de água livre existente no fruto faz com que seu rendimento seja baixo, já que grande parte dessa água é evaporada. Os demais frutos obtiveram rendimento em proporções semelhantes, com valores médios em torno de 20\% (Figura 4).



Figura 4. Rendimento das frutas após secagem

Curvas de desidratação por liofilização

O processo de liofilização requer um procedimento diferenciado, em relação à secagem em secador de fluxo contínuo. No primeiro caso, as frutas devem ser congeladas e em seguidas submetidas ao processo de liofilização de forma descontínua. Desta forma, não foi possível acompanhar a cada hora a perda de peso do fruto, havendo apenas a possibilidade de pesagem a cada 24 horas. Obteve-se, assim, curvas de secagem com apenas três pontos, como pode ser visto na Figura 5. 
Laurena Rayanne Vieira Moraes et al.
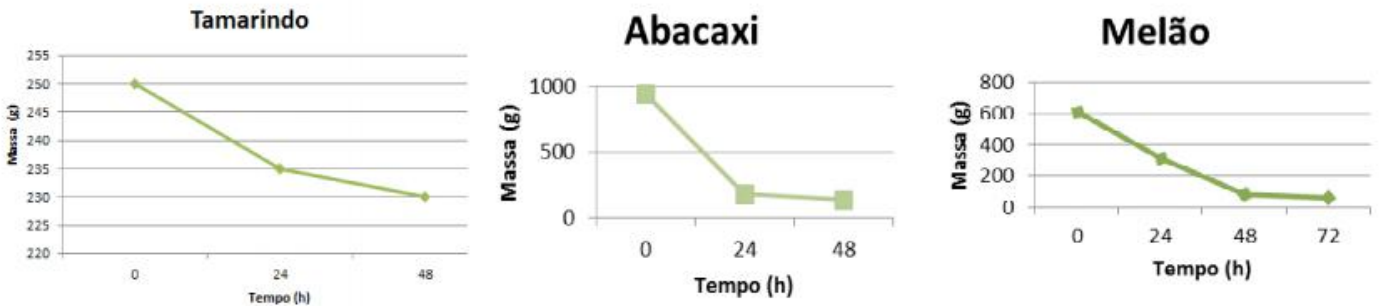

\section{Maracujá-do-mato}

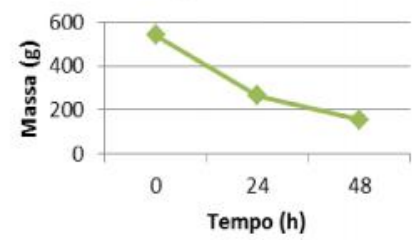

Maracujá

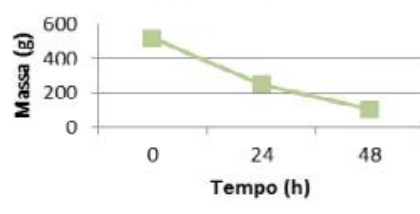

Residuo de Acerola



Figura 5. Curvas de secagem por liofilização dos frutos estudados

Para a maioria dos frutos foram liofilização. Ao compararmos com o método necessários 48 horas de liofilização, com exceção da manga e melão, que requeriram 72 horas para atingirmos o ponto ideal de secagem.

A Figura 6 mostra o percentual médio tradicional de secagem (Figura 4), podemos perceber comportamento semelhante para todas as frutas, havendo maior rendimento para o fruto do tamarindo e menor rendimento para os de rendimento dos frutos submetidos à frutos mais úmidos como manga e melão.



Figura 6. Rendimento das frutas após secagem por liofilização 
Laurena Rayanne Vieira Moraes et al.

\section{Análise Sensorial}

Os frutos desidratados e liofilizados foram submetidos à análise sensorial, após infusão em água quente, sendo avaliados a cor, aroma, sabor e características originais da fruta. Os resultados estão mostrados na Figura 7.
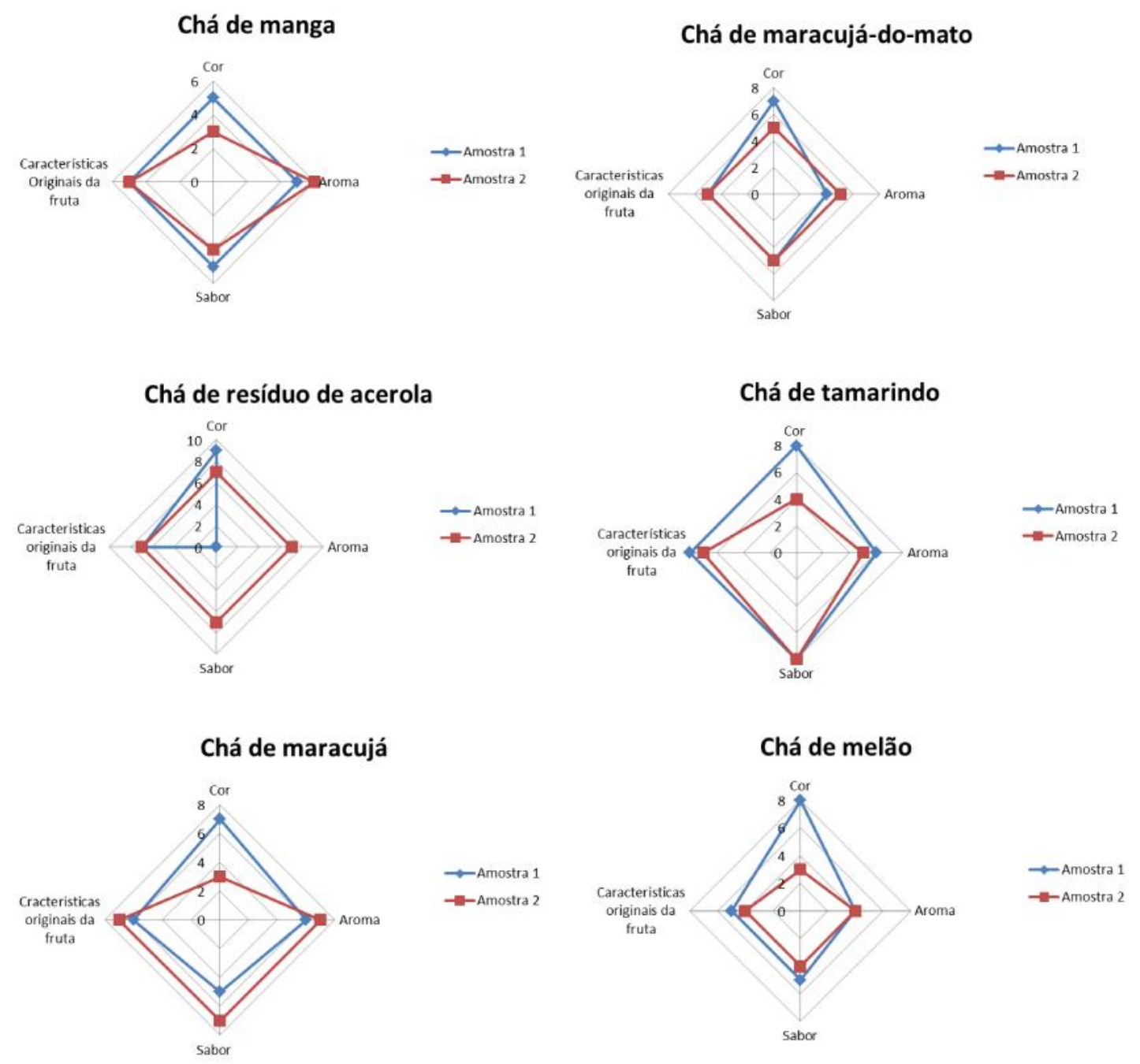

Chá de abacaxi

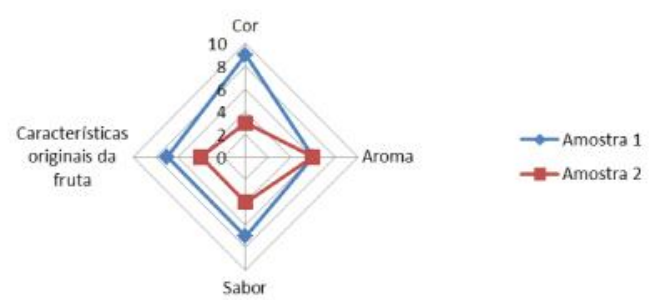

Figura 7. Gráfico de médias obtidas na análise sensorial de cada fruta submetida à secagem convencional (amostra 1) e liofilização (amostra 2)

É observável que para cada avaliação houveram resultados diferenciados quanto aos atributos avaliados, mas foi percebido que em todos os produtos, a amostra 1, que representa as frutas submetidas à secagem convencional, mostrou valores superiores no que se refere à 
Laurena Rayanne Vieira Moraes et al.

pontuação da cor. No que se refere ao parâmetro que avalia se o produto atingiu as expectativas sobre as características originais da fruta, as duas amostras obtiveram valores semelhantes e em alguns casos, valores iguais, exceto no chá de abacaxi que o valor foi bem diferenciado entre as duas amostras.

Quanto aos valores de aroma, as notas foram maiores ou iguais a 7 para a maioria das amostras, exceto para as amostras de chá de melão e de abacaxi que obtiveram valores inferiores a 5. Este resultado não poderá estar associado a perdas durante o processamento, uma vez que deve ser considerado que tais frutos não possuem naturalmente atributos aromáticos perceptíveis. Observa-se que não existe influencia negativa das duas técnicas de secagem sobre o aroma.
$\mathrm{Na}$ avaliação do sabor, as melhores notas foram atribuídas aos chás de tamarindo, maracujá e manga. $\mathrm{O}$ processo de liofilização favoreceu a pontuação do sabor, para a maioria dos chás estudados, cujas notas foram semelhantes ou ligeiramente maiores, quando comparados com os frutos desidratados por secagem convencional. Portanto, pode-se afirmar que o atributo "sabor" foi o mais preservado nos frutos liofilizados.

\section{Análise de Perfil de Compra}

Além das características sensoriais, os provadores inferiram quanto à intenção de compra das bebidas avaliadas. A Figura 8 revela o percentual de provadores que afirmou que "compraria" as bebidas na forma de chá.

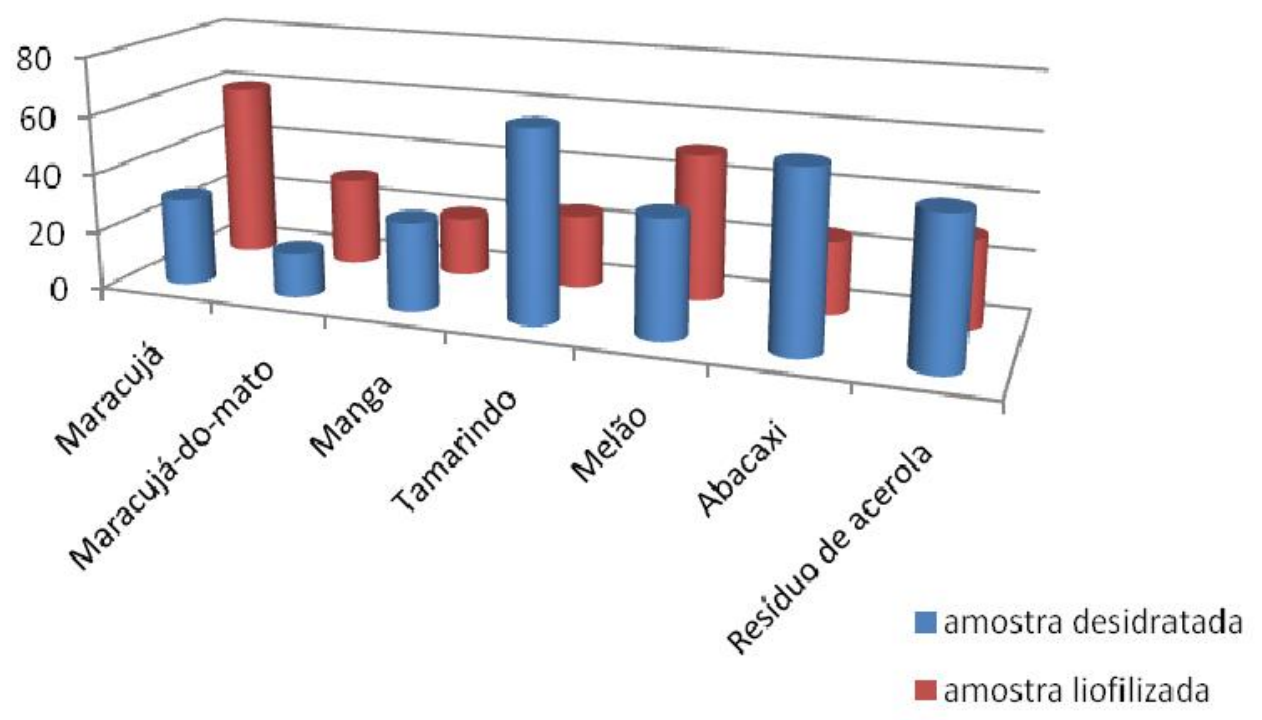

Em praticamente todas as amostras, exceto a de melão e dos dois tipos de maracujá (amarelo e maracujá-do-mato), a amostra desidratada por secagem em método convencional por fluxo de ar possuiu melhor aceitação segundo os provadores, já confirmado anteriormente pela discussão dos resultados de análise sensorial. Entre todas as amostras, só a de chá de manga que obteve maior valor de rejeição, uma vez que $20 \%$ dos provadores afirmaram que "não comprariam" o produto. No parâmetro "produto inovador", os produtos receberam $85-100 \%$ de aprovação. E no quesito "interessante" receberam 60-90\% de aceitação. Sendo observável a grande aceitação de todos os produtos, sendo assim apropriados e com grande possibilidade de comercialização.

\section{Conclusões}

Foi possível perceber que a secagem convencional apresenta algumas vantagens em relação ao método por liofilização, no que diz 
Laurena Rayanne Vieira Moraes et al.

respeito ao aroma e ao sabor das frutas secas obtidas, e integridade física se comparado ao fruto in natura. De maneira geral, todas as amostras de chá são consideradas apropriadas à comercialização, uma vez que possui qualidade tecnológica adequada para tal e aceitação verificada.

\section{Agradecimentos}

Ao $\mathrm{CNPq}$ pelo apoio financeiro, às professoras Luciana (orientadora) e Vivianni, bem como ao técnico de laboratório Ted Johnson pelo conhecimento que passaram, pela paciência, pelo auxilio. Ao Departamento de Engenharia de Produção da UNIVASF que cedeu o espaço físico para a realização deste projeto e aos funcionários do IF-SERTÃO PE que cooperaram para a análise sensorial.

\section{Referências}

BRASIL. Ministério da Saúde. Agência Nacional de Vigilância Sanitária. Resolução CNNPA n.12, de 24/07/1978 - Dispõe sobre normas técnicas especiais. Disponível em: www.anvisa.gov.br Acesso em 10 de julho de 2008.

CHAVES, M. C. V.; GOUVEIA, J. P. G.; ALMEIDA, F. A. C.; LEITE, J. C. A.; SILVA, F. L. H. Caracterização físico-química do suco da acerola. Revista de Biologia e Ciências da Terra, v. 4, n. 2, 2004.

FIGUEIRA, G. M.; SILVA, F.; MAGALHÃES, P. M.; PARK, K. J. Estudo da umidade de equilibrio de duas espécies de plantas do gênero Phyllanthus após secagem para o armazenamento. Revista Brasileira de Farmacognosia, v. 14, supl. 01, p. 22-24, 2004.

FILHO, S.F.S.O ; COSTA, E.F; XAVIER, L.F ; DIVERSIFICAÇÃO DA PRODUÇÃO E ACESSO A MERCADOS: ESTUDO DE CASO PARA A FRUTICULTURA IRRIGADA DO PÓLO PETROLINAJUAZEIRO. Disponível em:< http://www.sober.org.br/palestra/9/266.pdf > Acesso em: 19 de março de 2012

IAL. Normas Analíticas do Instituto Adolfo Lutz - Métodos Químicos e Físicos para Análise de Alimentos, $4^{\mathrm{a}}$ Ed. São Paulo, 2005.

NORTHOLD, M. D. et al. Patulin production by some fungal species in relation to water activity and temperature. Journal of Food Protection, Des Moines, v. 41, n.11, p.885890, 1978.

PARK, K.J; YADO,M.K.M; BROD,F.P.R ; Estudo de secagem de pêra bartlett (pyrus sp.) em fatias, Ciência e Tecnologia de Alimentos. vol.21 no.3 Campinas Sept./Dec. 2 001.

POTTER, N. N; HOTCHKISS, J. H. Constituyentes de los alimentos: propiedades y significado. In: _. Ciência de los Alimentos. 5a. ed. Zaragoza: Acribia, 1999. p. 29-50.

TACO. Tabela Brasileira de Composição de Alimentos. 4 ed. Campinas, 2011. UNICAMP 